\title{
Relationships among distribution, abundance and microhabitat specialisation in a guild of coral reef triggerfish (family Balistidae)
}

\author{
Kyi Bean*, Geoffrey P. Jones, M. Julian Caley \\ School of Marine Biology and Aquaculture, James Cook University, Townsville, Queensland 4811, Australia
}

\begin{abstract}
The potential relationship between ecological versatility and local distribution and abundance for 5 species of triggerfish was examined at Kimbe Bay, Papua New Guinea. The abundances of juvenile and adult Balistapus undulatus, Melichthys vidua, Rhinecanthus verrucosus, Sufflamen bursa and $S$. chrysopterus were quantified in a range of habitats along a typical coral reef profile. Four of the 5 species displayed distinct and relatively narrow distributions across the reef profile, with the fifth species, $B$. undulatus, being broadly distributed across all zones and depths, and the most abundant species. For each species, the spatial distribution of juveniles closely matched that of adults and juvenile densities were greater in species with more abundant adults. A detailed description of depth distributions of individuals indicated that shallow species had narrower depth ranges. In terms of microhabitat use, $B$. undulatus was the most generalised species, occupying all the microhabitats that were identified. The other 4 species were specialised to varying degrees on different microhabitats. Results from this study provide the first detailed description of patterns of distribution and abundance, habitat use and ecological versatility in triggerfish. Distribution and abundance could partially be explained by differences in the degree to which each species is specialised, both in terms of depth and microhabitat selectivity. Hence, versatility in depth and microhabitat use may play an important role in determining the local distribution and relative abundance of coral reef fishes.
\end{abstract}

KEY WORDS: Abundance $\cdot$ Distribution $\cdot$ Ecological specialisation $\cdot$ Habitat versatility $\cdot$ Resource availability $\cdot$ Coral reef fish $\cdot$ Balistidae

Resale or republication not permitted without written consent of the publisher

\section{INTRODUCTION}

Ecological communities are made up of species that vary in the degree to which they are specialised on the available resources (Fox \& Morrow 1981, Futuyma \& Moreno 1988, McNally 1995). The factors affecting the degree of specialisation and the consequences of differing levels of ecological versatility have received considerable theoretical attention (e.g. McNaughton \& Wolf 1970, McNally 1995, Morris 1996, Robinson \& Wilson 1998). Generalists potentially have access to greater amounts of resources and consequently may

${ }^{*}$ Present address: Department of Zoology, Downing Street, Cambridge University, Cambridge CB2 3EJ, United Kingdom.E-mail: kyibean@hotmail.com achieve a greater local abundance, a wider distribution among local habitats (i.e. over the reef profile) and a greater geographic range (McNaughton \& Wolf 1970, Brown 1984, Hengeveld 1990, McNally 1995, Hughes 2000). Specialists on the other hand, may be able to use certain resources more efficiently and may outcompete generalists in the acquisition of these resources (Emlen \& Oring 1977, Futuyma \& Moreno 1988). The ecological factors that may affect the relative costs and benefits of these 2 extremes are numerous with the theoretical relationship between resource specialisation, and the local distribution and abundance of species only recently tested (Hughes 2000).

Ecological versatility has been defined as 'the degree to which organisms can fully exploit the available resources in their local environment' (McNally 1995). 
In terms of habitats occupied, versatile species are expected to be ubiquitous, occupying a broad range of habitats, while specialised species are confined to a limited number of habitats. Information on the patterns and consequences of ecological versatility in coral reef fish communities is particularly scarce (Jones et al. 2002). These highly diverse communities appear to be comprised of the full spectrum of species, from specialists closely associated with a few coral or other invertebrate species (Arvedlund \& Nielsen 1996, Munday et al. 1997, Munday \& Jones 1998) to generalists capable of occupying a wide range of biotic and abiotic habitat types (Green 1996, Syms \& Jones 2000).

Relationships between reef fishes and habitat characteristics are best known for speciose families such as the gobies (e.g. Munday et al. 1997), damselfishes (Meekan et al. 1995), butterflyfishes (e.g. Hourigan 1989) and wrasses (e.g. Green 1996). Many species exhibit distinct patterns of habitat selection at settlement (Ormond et al. 1996). They may also display ontogenetic changes in resource utilisation, which may lead to major differences in the distribution and abundance of different life history stages (Lirman 1994, Green 1996). Hence, ontogenetic trends in the degree
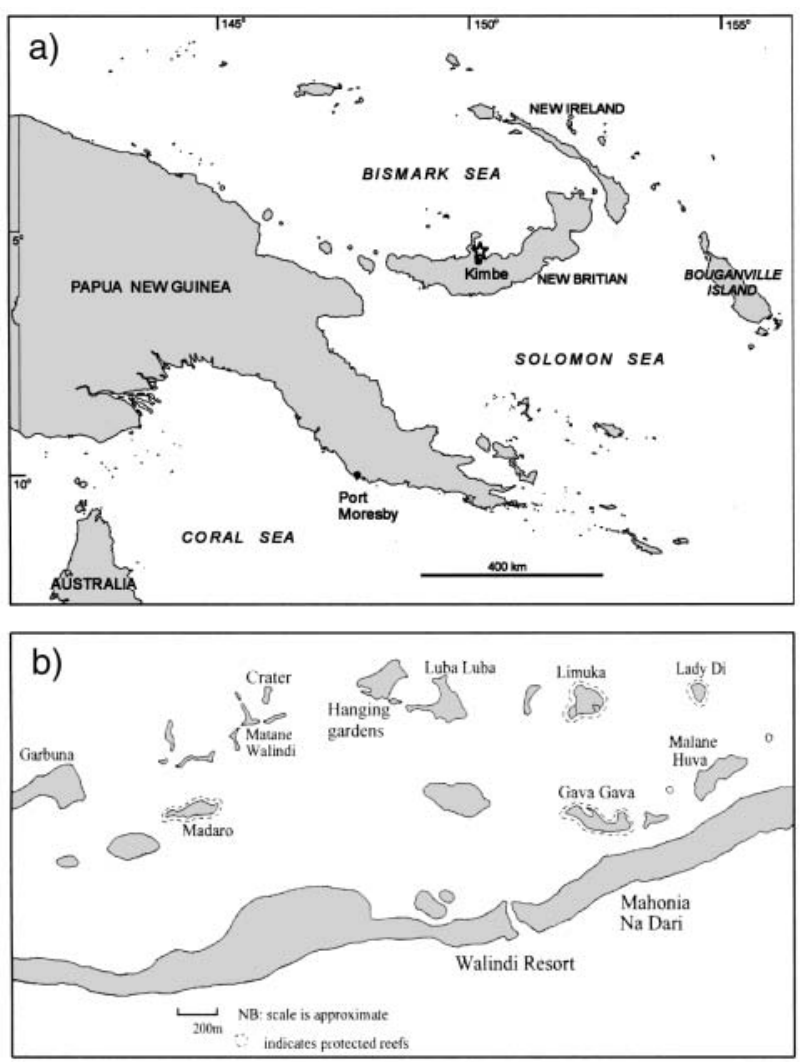

Fig. 1. (a) Map of Papua New Guinea $\left(5^{\circ} 25^{\prime} \mathrm{S}, 105^{\circ} 05^{\prime} \mathrm{E}\right)$ showing the position of New Britain Province (it indicates location of Fig. 1b); and (b) Reefs used in the visual census of triggerfish for zonation and depth distribution patterns of habitat versatility may be critical in evaluating the processes affecting the distribution and abundance of adults.

Little is known of the factors affecting the habitat use and the distribution and abundance of triggerfishes (family Balistidae) on coral reefs. For example, it is not known how juvenile and adult triggerfish are dispersed among reef zones and habitats in relation to one another, or which habitat types are used. While they are not as diverse or numerous as many other reef fish families, they may be extremely important as consumers in coral reef habitats (McClanahan \& Shafir 1990, McClanahan 1994). Balistids characteristically have highly omnivorous diets, with their strong teeth and jaws providing access to a wide range of plant and invertebrate food sources (Reinthal et al. 1984, Kuwamura 1991). However, they may acquire food resources by foraging in specialised habitats, with the family including both planktivorous and benthic feeding species (Randall et al. 1997). Hence, the balistid family may offer insights into the potential effects of ecological versatility on patterns of distribution and abundance.

In this study, we examined the potential relationships between microhabitat specialisation and local distribution and abundance patterns of juveniles and adults of 5 species of triggerfish at Kimbe Bay, Papua New Guinea. These were Balistapus undulatus, Melichthys vidua, Rhinecanthus verrucosus, Sufflamen bursa and $S$. chrysopterus. We made 2 predictions: (1) that species occupying a wide range of macrohabitats would reach greater local abundance (i.e. across the reef profile) than species restricted to a narrow range of habitats; and (2) distribution among macrohabitats and abundance would be greatest in species that are least specialised in terms of microhabitat and/or specific depth preferences. To evaluate these predictions, we first investigated the distribution and abundance of these species over a broad-scale, from the exposed front reef slope to sheltered back reef slope habitats. We then examined niche breadth in relation to a fine-scale description of depth strata and microhabitats used by individual fish, and determined how this related to broad-scale distribution and abundance.

\section{MATERIALS AND METHODS}

Study sites. This study was conducted in Kimbe Bay, West New Britain Province, Papua New Guinea, during February and March 1999 (5 $\left.5^{\circ} 25^{\prime} \mathrm{S}, 105^{\circ} 05^{\prime} \mathrm{E}\right)$ (Fig. 1a). Visual censuses of juveniles and adults of the 5 species of triggerfish over the reef profile were carried out on 4 discrete reefs: Garbuna, Madaro, Lady Di and Luba Luba (Fig. 1b). Each reef was divided into 
3 broad habitat zones according to its orientation and exposure: front (exposed fore reef slope), middle (reef flat) and back (protected back reef slope). To determine depth distribution patterns at a finer scale and over a greater depth range, 5 additional reefs were sampled (Matane Walindi, Limuka, Crater, Gava Gava and Hanging Gardens) (Fig. 1b).

Visual censuses of triggerfish. Visual surveys were used to quantify the abundance of triggerfish at 4 reefs (Fig. 1b). Four replicate belt transects $50 \times 4 \mathrm{~m}$ at depths of 0 to $1,2,6$ and $10 \mathrm{~m}$ were censused at front and back reef zones for each of the 4 reefs. The middle reef zones were censused using similar methods, but were only sampled at a depth of 0 to $1 \mathrm{~m}$. Tape measures were laid starting from a point parallel to the reef crest. Five metres were left between each transect at each depth. All triggerfish located within $2 \mathrm{~m}$ of the centre of the transect were identified to species and their size estimated to the nearest $1 \mathrm{~cm}$ standard length (SL). Size estimates were used to assign individuals into juvenile and adult categories. Diet and histological investigation of gonads indicated that the majority of individuals less than $6 \mathrm{~cm}$ SL consumed different prey items and were not reproductively mature compared to individuals greater than $6 \mathrm{~cm}$ SL (K. Bean unpubl. data). Juveniles of Melichthys vidua were, however, classified as individuals less than $12 \mathrm{~cm}$ SL as these individuals were still not reproductively mature and were consuming different prey items below this size class (K. Bean unpubl. data).

Depth estimates. Mean and variance in depth distributions were assessed in more detail by focal animal sampling over a greater depth range than that used for transects. Sampling involved descending to a depth of $20 \mathrm{~m}$ and slowly swimming in a zigzag pattern approximately $50 \mathrm{~m}$ wide from $20 \mathrm{~m}$ to the surface. These surveys were conducted in front and back reef zones. Each individual triggerfish observed was identified to species and its size estimated to the nearest $1 \mathrm{~cm}$ SL. The depth at which each fish was observed was recorded to the nearest metre by the same diver using the same depth gauge for each dive to remove variation associated with different observers and equipment. A total of 8 to 15 dives were conducted to determine the depths of 100 individuals of each species.

Habitat use and availability. For juveniles and adults of each of the 5 species of triggerfish, information on microhabitats occupied and availability was collected while carrying out transects and focal animal sampling. Microhabitat use was quantified by recording the substrata over which each individual was first observed during the visual census over the reef profile and while recording the depths of individual fish. In addition, on completion of the visual census of triggerfish on each transect, a second swim back along the transect was used to quantify habitat availability at each depth in each reef zone. This was quantified using 100 random points marked along the length of the transect tape.

Substratum type under each fish and random point was assigned to 1 of 15 substratum categories; sand, rubble, rock, macroalgae, turf algae, coralline algae, massive coral, foliaceous coral, columnar coral, encrusting coral, free living coral, branching coral, soft coral, sponges and solitary organisms (e.g. clams, sea anemones, shells).

Data analysis. Distribution and abundance of triggerfishes: The abundance of juvenile and adult Balistapus undulatus, Melichthys vidua and Sufflamen bursa (adults only) were each analysed separately using a 2-way analysis of variance (ANOVA) with reef zone (only the front and back reef zones were compared due to an unbalanced sample design) and depth as fixed factors. S. bursa and $S$. chrysopterus juveniles were not analysed in this way due to small sample size ( $\mathrm{n}=7$ and 10, respectively). A 1-way ANOVA was used to compare the abundance of adult $B$. undulatus and adult and juvenile Rhinecanthus verrucosus within the $0 \mathrm{~m}$ depth categories (between the reef crest, middle and back zones). A 1-way ANOVA was also used to compare the abundances of adult $S$. chrysopterus among depths within the back reef zone due to the restriction of this species to the back reef. Q-Q plots were examined to assess normality and Levene's test of equality of error variances was used to test for homogeneity of variance (Sokal \& Rohlf 1995). Where heterogeneity was detected, data were $\log _{10}(x+1)$ transformed. In all cases transformation stabilised variances. Unplanned multiple comparison tests using Tukey's HSD were used to test for sources of differences in within-species abundances of adult and juvenile triggerfish. The mean and variance in the depth distributions of each species over a wider depth range and at a finer scale were compared graphically.

Niche breadth: Czekanowski's Index (CI) was used to estimate the degree of similarity between the frequency distribution of habitat type used by individuals of each species and the frequency distribution of habitat available to those individuals. A niche breadth value (CI) for juveniles and adults of each of the 5 species of triggerfish was calculated using the formula:

$$
\mathrm{CI}=1-0.5 \sum_{i}\left|p_{i}-q_{i}\right|
$$

where $p_{i}$ is the proportion of resource items in state $i$ out of all items used by the population, and $q_{i}$ is the proportion of $i$ states in the resources base available to the population (Feinsinger et al. 1981).

Microhabitat selection. Use of resources by all 5 species in relation to availability was explored using 
Table 1. Two-way ANOVA's assessing abundance patterns of adult and juvenile Balistapus undulatus, Melichthys vidua and Sufflamen bursa (adults only) among the fore and back reef zones and depths. ${ }^{*} \mathrm{p}<0.05,{ }^{* *} \mathrm{p}<0.01,{ }^{* * *} \mathrm{p}<0.001$. NA: not applicable

\begin{tabular}{|c|c|c|c|c|c|}
\hline $\begin{array}{l}\text { Species } \\
\text { Source of variation }\end{array}$ & Type III SS & $\mathrm{df}$ & MS & $F$ & Tukey's HSD \\
\hline \multicolumn{6}{|l|}{ B. undulatus (adults) } \\
\hline Zone & 0.109 & 1 & 0.109 & 3.23 & \multirow{4}{*}{ NA } \\
\hline Depth & 0.09 & 3 & 0.03 & 0.98 & \\
\hline Depth $\times$ Zone & 0.556 & 3 & 0.185 & $5.48^{* *}$ & \\
\hline Error & 0.811 & 24 & 0.034 & & \\
\hline \multicolumn{6}{|l|}{ B. undulatus (juveniles) } \\
\hline Zone & 0.014 & 1 & 0.014 & 0.87 & \multirow{4}{*}{ NA } \\
\hline Depth & 0.553 & 3 & 0.184 & 1.16 & \\
\hline Depth $\times$ Zone & 0.237 & 3 & 0.079 & 0.50 & \\
\hline Error & 3.828 & 24 & 0.159 & & \\
\hline \multicolumn{6}{|l|}{ M. vidua (adults) } \\
\hline Zone & 0.325 & 1 & 0.325 & $4.83^{*}$ & \multirow{4}{*}{$\begin{array}{c}\text { Front }>\text { Back } \\
\text { NA }\end{array}$} \\
\hline Depth & 0.323 & 3 & 0.108 & 1.60 & \\
\hline Depth $\times$ Zone & 0.021 & 3 & 0.007 & 0.11 & \\
\hline Error & 1.614 & 24 & 0.067 & & \\
\hline \multicolumn{6}{|l|}{ M. vidua (juveniles) } \\
\hline Zone & 0.049 & 1 & 0.049 & 1.16 & \multirow{4}{*}{ NA } \\
\hline Depth & 0.083 & 3 & 0.028 & 0.65 & \\
\hline Depth $\times$ Zone & 0.096 & 3 & 0.032 & 0.76 & \\
\hline Error & 1.017 & 24 & 0.043 & & \\
\hline \multicolumn{6}{|l|}{ S. bursa (adults) } \\
\hline Zone & 1.423 & 1 & 1.423 & $29.6^{* * *}$ & \multirow{4}{*}{$\begin{array}{c}\text { Back }>\text { Front } \\
0<2=10<6 \mathrm{~m}\end{array}$} \\
\hline Depth & 1.999 & 3 & 0.666 & $13.9^{* * *}$ & \\
\hline Depth $\times$ Zone & 0.527 & 3 & 0.176 & $3.6^{*}$ & \\
\hline Error & 1.153 & 24 & 0.048 & & \\
\hline
\end{tabular}

resource selection ratios. Resource selection ratios were chosen as they provide an indication of use in relation to availability and can therefore be used to determine preference for certain habitat types (Manly et al. 1993). Manly et al.'s (1993) Model 1 with Protocol A was used because it requires that animals are not identified individually and the used, unused or available resource units are sampled randomly for the entire study area. A resource selection ratio was calculated separately for juveniles and adults of each species of triggerfish for every substratum category with which they were associated, using the formula:

$$
\hat{w}_{i}=o_{i} / \pi_{i}
$$

where $o_{i}$ equals the proportion of resources used and $\pi_{\mathrm{i}}$ equals the proportion of resources available (Manly et al. 1993). Due to multiple comparisons between resources, Bonferroni Z-corrections were used to calculate $95 \%$ confidence intervals using the formula:

$$
\left.\hat{W}_{i} \pm Z_{\alpha / 2} \sqrt{\left\{o_{i}\left(1-O_{i}\right) /\left(U_{+} \pi_{i}^{2}\right.\right.}\right\}
$$

where $Z_{\alpha / 2}$ is the critical value of the standard normal distribution corresponding to an upper tail area of $\alpha / 2$ and $U_{+}$is the number of used resources in all categories (Manly et al. 1993). The average percent cover of habitat in the reef zones and depths at which indi- viduals were located were compared with the mean number of times individuals were found to associate with each habitat type.

\section{RESULTS}

\section{Distribution and abundance of triggerfish}

Balistapus undulatus was the only species distributed across all habitats and depths. It also reached the greatest densities within any 1 macrohabitat (Fig. 2). There was no significant difference in the abundance of juvenile $B$. undulatus over reef zones or depths (Table 1). There was, however, a significant interaction between reef zone and depth for the abundance of adult $B$. undulatus (Table 1, Fig. 2). The densities of the other 4 species were generally lower and were restricted to a subset of reef zones and depths (Fig. 2).

Adult Melichthys vidua were significantly more abundant on the reef crest at a depth of $2 \mathrm{~m}$ and were notably absent from the middle reef top while occurring only at a depth of $2 \mathrm{~m}$ on the back reef (Fig. 2, Table 1). The abundance of juveniles of $M$. vidua did not differ significantly among reef zones or depths 
(Table 1), occurring over a larger range of zones and depths than adults (Fig. 2).

Adult and juvenile Rhinecanthus verrucosus were restricted to the reef top (Fig. 2). Although adult $R$. verrucosus reached greater abundance at the reef middle versus the reef front, this was not significantly different (Table 2, Fig. 2). Juvenile $R$. verrucosus, however, were more abundant on the back reef compared to the front reef zone (Table 2).

Adult Sufflamen bursa occurred on both the front and back reef below $2 \mathrm{~m}$ (Fig. 2), yet were significantly more abundant at the back reef zone and at depths of 6 to $10 \mathrm{~m}$ (Table 1, Fig. 2). The total number of juvenile $S$. bursa sampled was low, but their distribution closely matched that of adults (Fig. 2). In contrast, adult $S$. chrysopterus occurred in slightly shallower depth strata than $S$. bursa on the back reef (Fig. 2). Adults were significantly more abundant on the back reef at a depth of $2 \mathrm{~m}$ (Table 2) and were absent from both the middle and front reef zones (Fig. 2). Juvenile S. chrysopterus occurred over all zones but were restricted to a depth of 0 to $2 \mathrm{~m}$ (Fig. 2).

\section{Depth distribution and microhabitat use}

Fine-scale depth estimates for individual fish provided a more direct estimate of the degree to which different species are specialised on different depth strata. A visual comparison of depth distribution patterns among species indicated that Balistapus undulatus and Sufflamen bursa are generalists with respect to depth, being found at all depths sampled (Fig. 3). All other species were restricted to a narrower depth range (Fig. 3). Melichthys vidua occurred over a depth range of 0 to $9 \mathrm{~m}$, occurring at a similar mean depth to

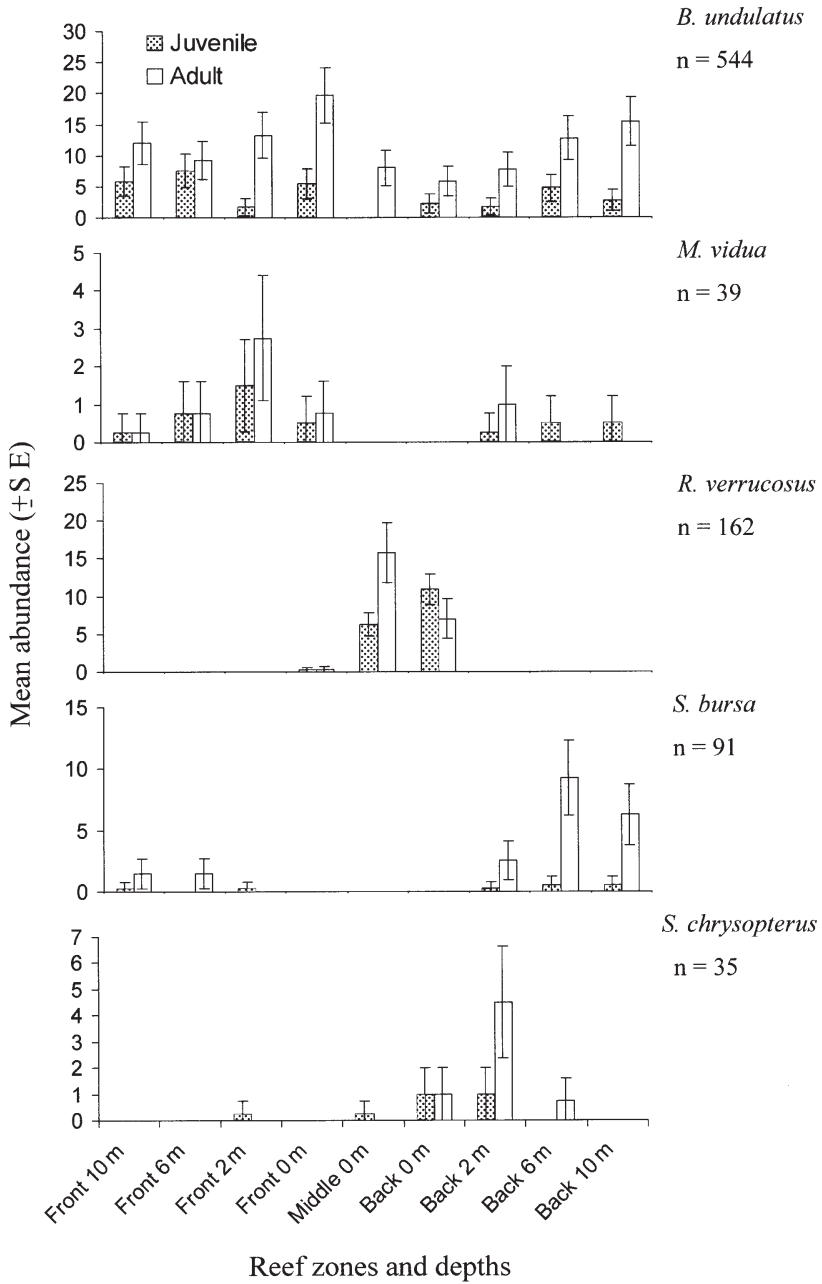

Fig. 2. Mean abundance $( \pm \mathrm{SE})$ per $3200 \mathrm{~m}^{2}$ of juvenile and adult Balistapus undulatus, Melichthys vidua, Rhinecanthus verrucosus, Sufflamen bursa and S. chrysopterus across reef zones and depths

Table 2. One-way ANOVA's assessing abundance patterns of adult Balistapus undulatus and juvenile and adult Rhinecanthus verrucosus among $0 \mathrm{~m}$ depth categories among reef zones, and adult Sufflamen chrysopterus among depths at the back reef zone. ${ }^{*} \mathrm{p}<0.05,{ }^{* *} \mathrm{p}<0.01$. NA: not applicable

\begin{tabular}{|c|c|c|c|c|c|}
\hline $\begin{array}{l}\text { Species } \\
\quad \text { Source of variation }\end{array}$ & SS & $\mathrm{df}$ & MS & $F$ & Tukey's HSD \\
\hline \multicolumn{6}{|l|}{ B. undulatus (adults) } \\
\hline Zone & 0.642 & 2 & 0.321 & \multirow[t]{2}{*}{0.28} & \multirow[t]{2}{*}{ NA } \\
\hline Error & 1.036 & 9 & 0.115 & & \\
\hline \multicolumn{6}{|l|}{$R$. verrucosus (adults) } \\
\hline Zone & 2.200 & 2 & 0.895 & \multirow[t]{2}{*}{3.66} & \multirow[t]{2}{*}{ NA } \\
\hline Error & 1.789 & 9 & 0.244 & & \\
\hline \multicolumn{6}{|l|}{$R$. verrucosus (juveniles) } \\
\hline Zone & 1.568 & 2 & 0.784 & \multirow[t]{2}{*}{$4.72^{*}$} & \multirow[t]{2}{*}{ Middle $=$ Back $>$ Fore } \\
\hline Error & 1.495 & 9 & 0.166 & & \\
\hline \multicolumn{6}{|l|}{ S. chrysopterus (adults) } \\
\hline Depth & 0.424 & 3 & 0.378 & \multirow[t]{2}{*}{$10.7^{* *}$} & \multirow[t]{2}{*}{$0<2>6 \mathrm{~m}$} \\
\hline Error & 1.134 & 12 & 0.035 & & \\
\hline
\end{tabular}




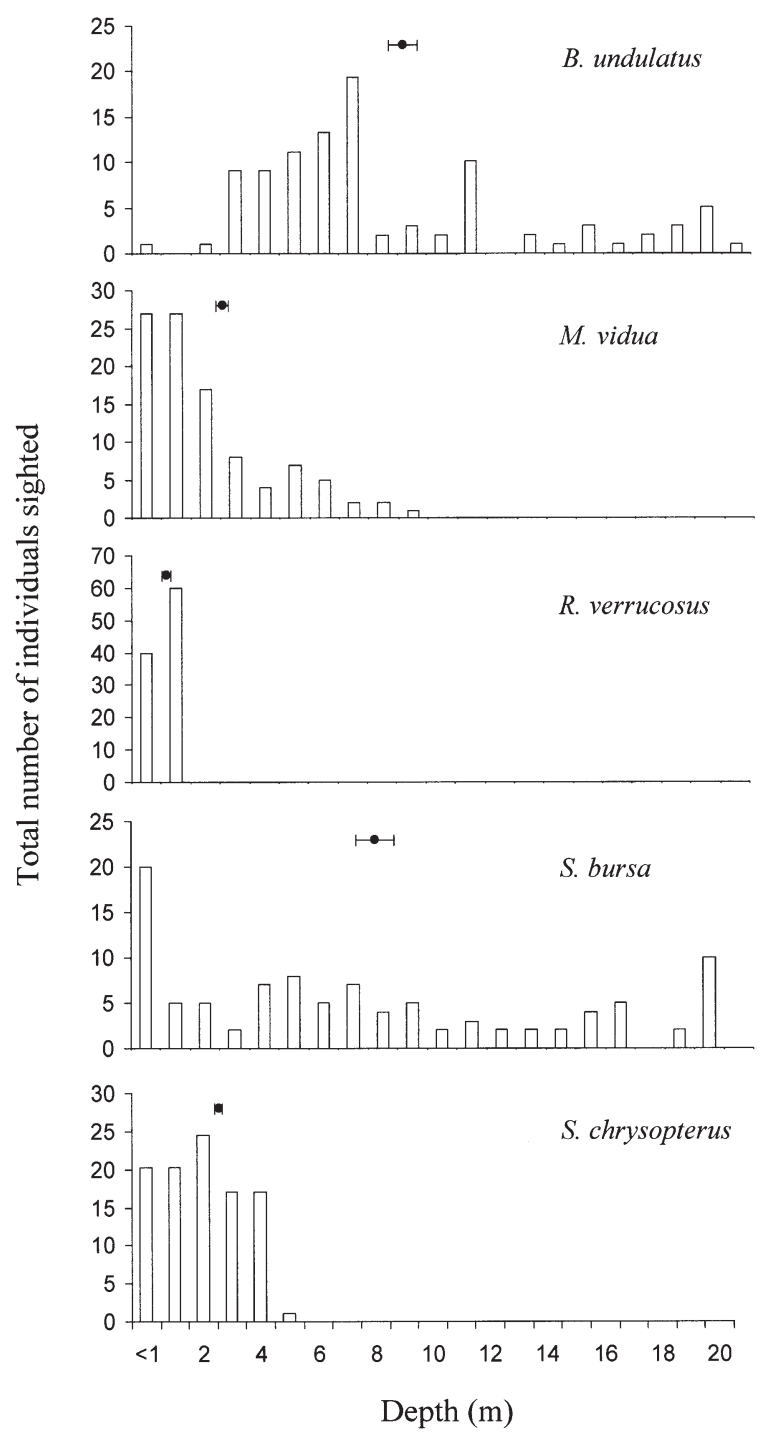

Fig. 3. Depth distribution of Balistapus undulatus, Melichthys vidua, Rhinecanthus verrucosus, Sufflamen bursa and $S$. chrysopterus along a $20 \mathrm{~m}$ depth gradient. Means and standard errors are depicted. $\mathrm{n}=100$ for each species

that of S. chrysopterus (Fig. 3). The most depthrestricted species was Rhinecanthus verrucosus, which occurred no deeper than $1 \mathrm{~m}$ (Fig. 3).

Niche breadth estimates revealed that the most abundant and broadly distributed species, Balistapus undulatus, was also the most generalised species in terms of its microhabitat use (Fig. 4). Those species which were less abundant and which were restricted to particular reef zones and depths had lower niche breadth values indicative of more specialised habitat use within the habitats they occupy (Fig. 4). Juveniles of all species except Rhinecanthus verrucosus, were slightly more restricted in their microhabitat use than conspecific adults (Fig. 4).
Use of available habitat indicated that juveniles and adults of the most abundant species, Balistapus undulatus, used the greatest number of substratum types (Table 3). Even though B. undulatus occupied a wide variety of substratum types, adults used rock, foliaceous coral, and branching coral more frequently than expected on the basis of availability (Table 3). Juvenile $B$. undulatus, however, used turf algae, sponge, sand, macroalgae, encrusting and soft coral more frequently than expected (Table 3, Figs. 5 \& 6).

In contrast to Balistapus undulatus, juveniles and adults of the other 4 species used a smaller number of resources (Table 3). Adult Melichthys vidua were most often associated with massive and branching corals although they were found on other substrata (Table 3). Juveniles of this species were more specialised, using only 5 substratum types and using rock more frequently than expected by chance (Table 3, Fig. 6). Adult Rhinecanthus verrucosus were associated with macroalgae, rubble and sand more frequently than expected on the basis of availability (Table 3, Fig. 5). Juvenile $R$. verrucosus used a smaller number of resources $(n=5)$, also using rubble and macroalgae more frequently than expected (Table 3). Adult Sufflamen bursa appeared to avoid massive coral, branching coral, coralline algae and turf algae, while using rubble and sand more frequently than expected if nonselective (Table 3). Juveniles were restricted to sand and rubble substrata, using them more frequently than expected on the basis of availability (Table 3). Like adult $S$. bursa, adult $S$. chrysopterus occupied rubble and sand more often than availability would suggest, and used turf algae less frequently than expected (Table 3, Fig. 5). In contrast, juvenile S. chrysopterus used 4 substratum categories, using rubble more frequently than expected (Table 3, Fig. 6).

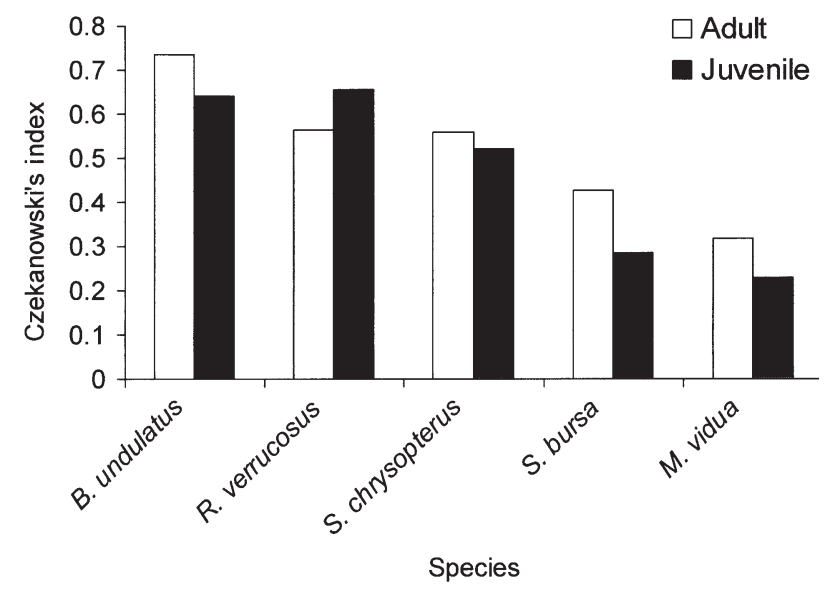

Fig. 4. Czekanowski's niche breadth index for juvenile and adult Balistapus undulatus, Melichthys vidua, Rhinecanthus verrucosus, Sufflamen bursa and S. chrysopterus 
Table 3. Outcomes of resource selection ratio calculations for habitat selection within reef zones and depths occupied by juveniles (J) and adults (A) of each of the 5 species of triggerfish. (+: habitat is being used more frequently than available; -: habitat is being used less frequently than available; ns indicates that a habitat is used in accordance with availability; and 0 indicates that a habitat is not used). FL = free living

\begin{tabular}{|c|c|c|c|c|c|c|c|c|c|c|}
\hline \multirow{3}{*}{$\begin{array}{l}\text { n: } \\
\text { Habitat: }\end{array}$} & \multicolumn{2}{|c|}{$\begin{array}{l}\text { Balistapus } \\
\text { undulatus }\end{array}$} & \multicolumn{2}{|c|}{$\begin{array}{l}\text { Melichthys } \\
\text { vidua }\end{array}$} & \multicolumn{2}{|c|}{$\begin{array}{c}\text { Rhinecanthus } \\
\text { verrucosus }\end{array}$} & \multicolumn{2}{|c|}{$\begin{array}{l}\text { Sufflamen } \\
\quad \text { bursa }\end{array}$} & \multicolumn{2}{|c|}{$\begin{array}{c}\text { Sufflamen } \\
\text { chrysopterus }\end{array}$} \\
\hline & 132 & 479 & 17 & 131 & 85 & 259 & 15 & 166 & 37 & 92 \\
\hline & $\mathrm{J}$ & $\mathrm{A}$ & $\mathrm{J}$ & $\mathrm{A}$ & $\mathrm{J}$ & $\mathrm{A}$ & $\mathrm{J}$ & $\mathrm{A}$ & $\mathrm{J}$ & A \\
\hline Branching & - & + & ns & + & 0 & - & 0 & - & 0 & - \\
\hline Columnar & - & - & 0 & - & 0 & 0 & - & $\mathrm{ns}$ & - & $\mathrm{ns}$ \\
\hline Coralline & - & ns & 0 & - & 0 & 0 & 0 & - & 0 & 0 \\
\hline Encrusting & + & - & 0 & - & 0 & 0 & 0 & 0 & 0 & 0 \\
\hline Foliaceous & - & + & 0 & - & 0 & 0 & 0 & 0 & 0 & - \\
\hline Laminar & - & ns & 0 & - & 0 & 0 & 0 & 0 & 0 & 0 \\
\hline Macroalgae & + & - & 0 & ns & + & + & 0 & - & 0 & 0 \\
\hline Massive & ns & ns & - & + & 0 & - & 0 & - & - & - \\
\hline Rock & - & + & - & + & 0 & 0 & 0 & 0 & 0 & - \\
\hline Rubble & ns & ns & - & ns & + & + & + & + & + & + \\
\hline Sand & + & ns & 0 & - & - & + & + & + & - & + \\
\hline Sponge & + & ns & 0 & - & - & 0 & 0 & 0 & 0 & - \\
\hline FL coral & - & - & 0 & 0 & 0 & 0 & 0 & - & 0 & 0 \\
\hline Soft coral & + & ns & 0 & - & 0 & 0 & 0 & 0 & 0 & 0 \\
\hline Turf algae & + & ns & 0 & - & $\mathrm{ns}$ & $\mathrm{ns}$ & 0 & $\mathrm{~ns}$ & ns & ns \\
\hline Dead coral & - & - & ns & 0 & 0 & 0 & 0 & - & 0 & 0 \\
\hline
\end{tabular}

\section{DISCUSSION}

The distribution and abundance of Balistapus undulatus differs markedly from the other 4 triggerfishes examined in this study. B. undulatus exhibited the broadest distribution among reef zones, the greatest local densities and relatively uniform patterns of abundance, suggesting that on a macrohabitat scale $B$. undulatus is a generalist species. B. undulatus is also the most versatile species in terms of its microhabitat use among reef zones. It was observed on all substrata that we distinguished in our sampling design, and to a large extent, appeared to use them indiscriminately.

The 4 less abundant species exhibited narrow and distinct patterns of zonation across reef zones, with maximum abundance concentrated in different macrohabitats. Rhinecanthus verrucosus is a reef top specialist, Melichthys vidua a fore reef slope specialist and the 2 Sufflamen species are back reef slope specialists. For the 5 species examined here, the pattern observed was consistent with Brown's (1984) observation that when closely related individuals of the same guild are compared, those species that have the highest local abundance tend also to have wider distribution patterns.

Fig. 5. Proportion of habitat used by adult Balistapus undulatus, Melichthys vidua, Rhinecanthus verrucosus, Sufflamen bursa and $S$. chrysopterus compared with the availability of those substrata within the reef zones and depths each species occurred

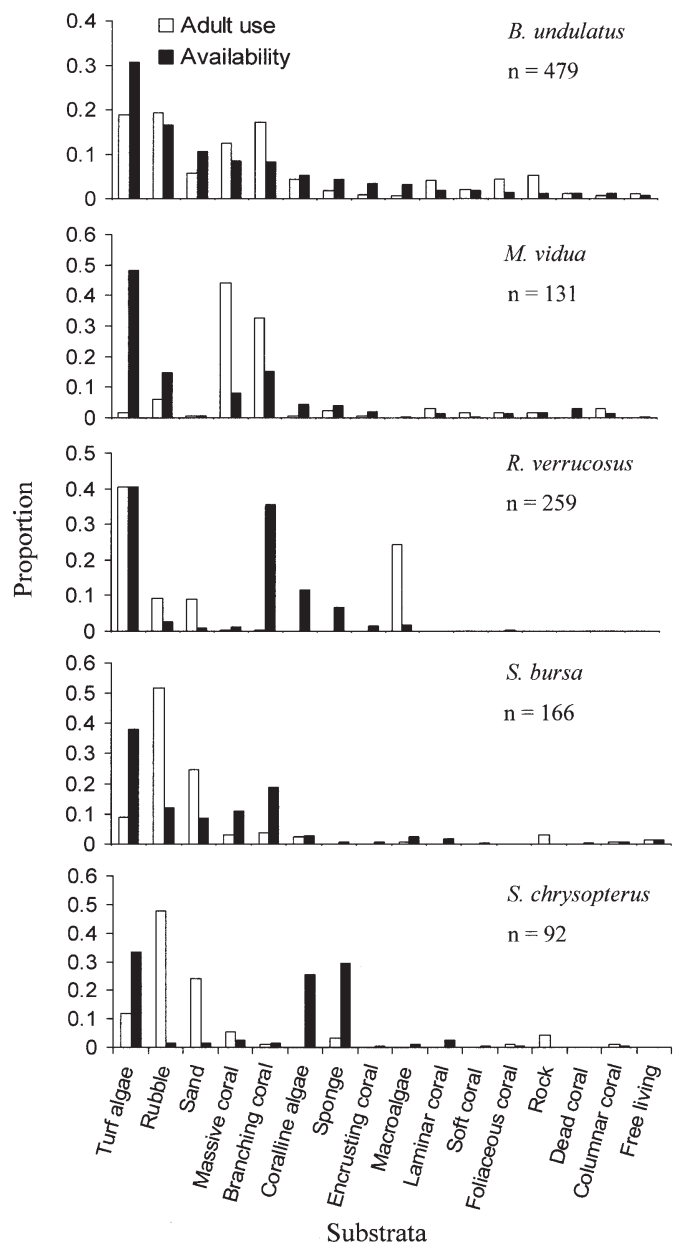




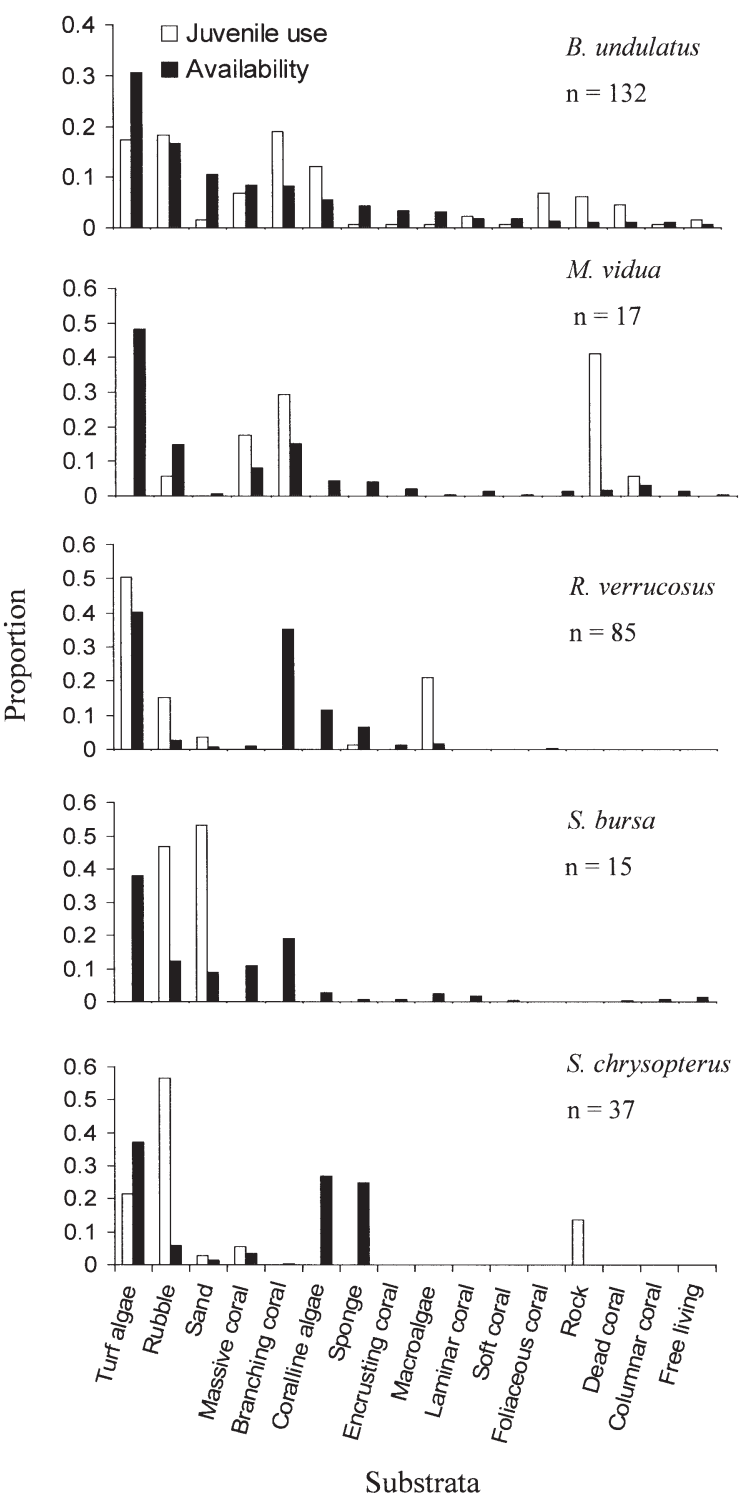

Fig. 6. Proportion of habitat used by juvenile Balistapus undulatus, Melichthys vidua, Rhinecanthus verrucosus, Sufflamen bursa and $S$. chrysopterus compared with the availability of those substrata within the reef zones and depths each species occurred

Depth distribution patterns also suggest that Balistapus undulatus is one of the most versatile species in this guild. While $B$. undulatus appears to prefer depths of 2 to $8 \mathrm{~m}$, it was regularly found to at least $20 \mathrm{~m}$ with Sufflamen bursa also found over this depth range. Comparing all species, there appears to be a pattern of increasing variance in the depth range with increasing average depth. That is, there were no examples of a deep species with a narrow depth range. It is possible that distributions among macrohabitats are explained by differences among species in their ability to use deeper water, regardless of habitat structure. However, different abilities between species to use deeper water would not explain the differences in the distribution of some species between front and back reef habitats. Clearly, depth and habitat structure are closely linked and further work is required to isolate their effects over the whole reef profile.

The preference of adult Melichthys vidua for massive coral, and in particular front reef locations, may be related to $M$. vidua being a planktivore, compared to the other species which are omnivores (K. Bean unpubl. data). By occupying a shallow position on reef fronts, exposure to currents carrying plankton would likely be increased (Hobson 1991). Preference for massive coral may therefore reflect high abundance in this area and its subsequent use by $M$. vidua as a shelter site, rather than for food acquisition. Juvenile $M$. vidua displayed a similar distribution pattern to adults although they were more often associated with branching coral. Again, preference for substrata of higher topographic complexity may be greater at the juvenile stage when they may be more susceptible to predators (Hixon \& Beets 1993, Caley \& St. John 1996).

In contrast, Rhinecanthus verrucosus was restricted to reef tops and therefore had the narrowest depth distribution. Adult and juvenile $R$. verrucosus were associated with macroalgae and rubble more frequently than expected. The peak in abundance of adult and juvenile $R$. verrucosus, however, occurred at different locations on the reef top. Other factors such as competitive interactions or differential habitat requirements between juveniles and adults may influence the observed pattern, resulting in disjunct distributions. Competitive interactions between adults and juveniles where resource requirements overlap has been found in previous studies to result in juveniles being excluded from adult habitats (Jones 1987, Levin 1993). Hence, an understanding of behavioural interactions between adults and juveniles may be required to understand distribution patterns of $R$. verrucosus within the reef top zone. Alternatively, differences in diet and the distribution of food items may influence differences in the distribution of adult and juvenile $R$. verrucosus. Prey availability has previously been shown to be important in determining the distribution of the grey triggerfish Balistes capriscus, for which there was a positive relationship between sand dollar abundance and the abundance of adult triggerfish (Kurz 1995). Diet may therefore influence patterns of distribution due to differences in the distribution of preferred prey items.

Sufflamen bursa and $S$. chrysopterus exhibited disjunct distributions on the back reef slope, with very little overlap in their depth distributions. Both species, 
however, displayed high overlap in habitat use, preferring sand and rubble as both juveniles and adults, and occurring primarily in the back reef zone. High overlap in habitat use suggests that depth distribution patterns on the back reef zone may be affected by competitive interactions between the 2 Sufflamen species (Ebeling \& Laur 1986). Behavioural interactions may therefore be an important mechanism shaping the distribution patterns of $S$. bursa and $S$. chrysopterus across the reef profile, where the competitively dominant species may occupy the preferred depth, pushing the other species into deeper or shallower water. In this case, the more specialised of the 2 species would be expected to out-compete the more generalised species (Futuyma \& Moreno 1988).

The guild of balistids studied here provides some insight into how distribution and abundance patterns may be influenced by microhabitat specialisation and the availability of resources. Although this study provides one of the first tests of ecological versatility for coral reef fish, other factors may be influencing the observed degree of specialisation, including interactions among and within fish species. A greater range of species from this and other taxa, however, must be examined to confirm this pattern. Therefore, experimental studies are needed to test whether such behavioural interactions influence microhabitat use. For example, can the 4 specialist species out-compete Balistapus undulatus within their preferred habitat zones? Clearly, local patterns of distribution and abundance are likely to result from complex interactions among species, competitors and resources. Disentangling these potential causes of observed distributions is worthy of greater attention in the future.

Acknowledgements. We thank the staff of the School of Marine Biology and Aquaculture who provided technical support and the staff at the Mahonia Na Dari Research Station and Walindi Plantation Resort in Papua New Guinea for the use of their facilities while conducting fieldwork. Thanks also to Maya Shrinivasan, Dean Miller, Craig Syms and Janelle Eagle for their assistance with fieldwork. This research was funded by the Australian Research Council and James Cook University.

\section{LITERATURE CITED}

Arvedlund M, Nielsen LE (1996) Do the anemonefish Amphiprion ocellaris (Pisces: Pomacentridae) imprint themselves to their host sea anemone Heteractis magnifica (Anthozoa: Actinidae). Ethology 102:35-42

Brown JH (1984) On the relationship between abundance and distribution of species. Am Nat 124:255-279

Caley MJ, St. John J (1996) Refuge availability structures assemblages of tropical reef fishes. J Anim Ecol 65: $414-428$

Ebeling AW, Laur DR (1986) Foraging in surfperches: re- source partitioning or individualistic responses? Environ Biol Fishes 16:123-133

Emlen ST, Oring LW (1977) Ecology, sexual selection, and the evolution of mating systems. Science 197:215-223

Feinsinger P, Spears EE, Poole RW (1981) A simple measure of niche breadth. Ecology 62:27-12

Fox LR, Morrow PA (1981) Specialisation: species property or local phenomenon? Science 211:887-893

Futuyma DJ, Moreno G (1988) The evolution of ecological specialisation. Annu Rev Ecol Syst 19:207-233

Green AL (1996) Spatial, temporal and ontogenetic patterns of habitat use by coral reef fishes (Family Labridae). Mar Ecol Prog Ser 133:1-11

Hengeveld R (1990) Dynamic biogeography. Cambridge University Press, Cambridge

Hixon MA, Beets JP (1993) Predation, prey refuges, and the structure of coral-reef fish assemblages. Ecol Monogr 63: $77-101$

Hobson ES (1991) Trophic relationships of fishes specialised to feed on zooplankters above coral reefs. In: Sale PF (ed) The ecology of fishes on coral reefs. Academic Press, San Diego, p 69-81

Hourigan TF (1989) Environmental determinants of butterfly social systems. Environ Biol Fishes 25:61-78

Hughes JB (2000) The scale of resource specialisation and the distribution and abundance of lycaenid butterflies. Oecologia 123:375-383

Jones GP (1987) Competitive interactions among adults and juveniles in a coral reef fish. Ecology 68:1534-1547

Jones GP, Caley MJ, Munday PL (2002) Rarity in coral reef fish communities. In: Sale PF (ed) Coral reef fishes: dynamics and diversity in a complex ecosystem. Academic Press, San Diego, p 81-102

Kurz RC (1995) Predator-prey interactions between grey triggerfish (Balistes capriscus Gmelin) and a guild of sand dollars around artificial reefs in the north-eastern Gulf of Mexico. Bull Mar Sci 56:150-160

Kuwamura T (1991) Habitat segregation, coexistence or interspecific territoriality between two triggerfishes, Rhinecanthus aculeatus and Sufflamen chrysopterus, with notes on distribution of other Balistids at Sesoko Island, Okinawa. Galaxea 10:65-78

Levin PS (1993) Habitat structure, conspecific presence and spatial variation in the recruitment of a temperate reef fish. Oecologia 94:176-185

Lirman D (1994) Ontogenetic shifts in habitat preferences in the three-spot damselfish, Stegastes planifrons (Cuvier), in Roatan Island, Honduras. J Exp Mar Biol Ecol 180: $71-81$

Manly BFJ, McDonald LL, Thomas DL (1993) Resource selection by animals. Statistical design and analysis for field studies. Chapman and Hall, London

McClanahan TR (1994) Kenyan coral reef lagoon fish: effects of fishing, substrate complexity, and sea urchins. Coral Reefs 13:231-241

McClanahan TR, Shafir SH (1990) Causes and consequences of sea urchin abundance and diversity in Kenyan coral reef lagoons. Oecologia 83:362-370

McNally RC (1995) Ecological versatility and community ecology. Cambridge University Press, Cambridge

McNaughton SJ, Wolf LL (1970) Dominance and the niche in ecological systems. Science 167:131-139

Meekan MG, Steven ADL, Fortin MJ (1995) Spatial patterns in the distribution of damselfishes on a fringing coral reef. Coral Reefs 14:151-161

Morris DA (1996) Coexistence of specialist and generalist rodents via habitat selection. Ecology 77:2352-2364 
Munday PL, Jones GP (1998) The ecological implications of small body size among coral-reef fishes. Oceanogr Mar Biol Annu Rev 36:373-411

Munday PL, Caley JM, Jones JP (1997) Bi-directional sex change in a coral dwelling goby. Behav Ecol Sociobiol 43: 371-377

Ormond RFG, Roberts JM, Jan RQ (1996) Behavioural differences in microhabitat use by damselfishes (Pomacentridae): implications for coral reef fish biodiversity. J Exp Mar Biol Ecol 202:85-95

Randall JE, Allen GR, Steene RC (1997) Fishes of the Great Barrier Reef and the Coral Sea. Crawford House Publishing, Bathurst

Editorial responsibility: Otto Kinne (Editor),

Oldendorf/Luhe, Germany
Reinthal PN, Kensley B, Lewis SM (1984) Dietary shifts in the queen triggerfish, Balistes vetula, in the absence of its primary food item, Diadema antillarum. PSZN I: Mar Ecol 5: 191-195

Robinson BW, Wilson DS (1998) Optimal foraging, specialisation, and a solution to Liem's Paradox. Am Nat 151: 223-235

Sokal RR, Rohlf FJ (1995) Biometry. The principles and practice of statistics in biological research. WH Freeman and Co, New York

Syms C, Jones GP (2000) Disturbance, habitat structure and the dynamics of a coral reef fish community. Ecology 81: $2714-2729$

Submitted: April 25, 2001; Accepted: November 1, 2001 Proofs received from author(s): April 12, 2002 